\title{
An Exploration of Gender Based Differences in Workplace Values
}

\author{
Fapohunda, Tinuke. M \\ Department of Industrial Relations and Public Administration \\ Lagos State University Ojo. Nigeria \\ Email: tkfap@yahoo.com
}

Accepted: August 16, 2013 Published: Sep 04, 2013

Doi:10.5296/ijhrs.v3i3.4228 URL: http://dx.doi.org/10.5296/ijhrs.v3i3.4228

\begin{abstract}
A b s t r a c t
Possible gender differences in the workplace are always a hot topic because they might explain why men continue to dominate in the jobs arena, despite the significant headway being made by women. Recent data indicate that males and females have somewhat differing priorities in their jobs but share basic ideas of what they think is important. Some research has shown that a supposed values gap between male and female workers does not explain away why men continue to enjoy greater career advancement than women. Social scientists have also theorized that work environments can embody both "male" and "female" characteristics, which may impact job satisfaction. Taking steps to better understand worker's values can bring about important advantage in developing workable and well-supported policies. Understanding what men and women value in a job is important to designing effective approaches to human resource management and in skill development initiatives.
\end{abstract}

Keywords: Exploration, Gender, Based, Differences, Workplace, Values

\section{Introduction}

Gender is an essential part of our modern vocabulary and is clearly defined as the relationship between women and men, how societies and cultures determine what is masculine or feminine and how power is allocated and used differently by men and women. The complexity and multi-layered realities of gender in our society need to be deconstructed for us to be able to work towards creating an equitable future.Just as development is not gender sensitive, neither are all organizations. Women in society are often marginalized and relegated to the completion of their reproductive work. Women working in formal organizations are most often in the roles of secretaries, assistants and support staff that do not allow them to break out of existing stereotypes. Other positions they occupy in the organizational structure itself as well as organizational cultures themselves operates differently for men and women. Sometimes organizations are either gender neutral or gender blind, but often times the desire of exhibiting gender sensitivity towards one gender become obsessively biased against another gender. 
Values are beliefs, missions, or philosophies that are really meaningful to a person. Whether consciously aware of them or not, every individual has a number of values. Such values range from the commonplace, such as the belief in hard work, self-reliance and harmony of purpose. In situations of choice between 'tempting' or equally 'reasonable' options or alternatives and possibilities, values, among other factors, determine choices. The importance of values lies in the fact that they are central to the establishment of ongoing behaviour patterns. Values represent strongly held beliefs about how the world should be, how people should normally behave, and preferred conditions of life. Taking steps to better understand worker's values can bring about important advantage in developing workable and well-supported policies. Guth and Taguiri (2007) asserts that the values most important to workers have a profound influence on their decisions.

Attention to workplace values assists human resource managers to become more self-aware, make ethical decisions, prioritize tasks, and develop credibility. Management is in search of individuals who will lift organizations above mere performances and optimal achievement of goals to super performances and extra-ordinary profit. Workplace values serve as determinants for decision making, choice and action. People behave in accordance with their values and their choices are dictated by their value system. Values have implications for enterprise strategy and workplace values make a difference in terms of how information is evaluated, how decisions are made and what behaviours are exhibited. Workplace value systems influence the extent to which organizational pressures, goals as well as achievements are accepted or rejected. The relevance of workplace values as determinants and guidelines for decision and action is not in doubt because workers essentially act and look at the world through the glass of their values.

The central interest in this study is the implication of gender differences in workplace values. A study on gender-based workplace preferences, conducted by Lluminari, Inc., employing more than 1,000 workers found that both men and women tend to value the same things at work, but with different emphasis.

\section{Objectives of the Study}

The study examines the notion that gender-based values influence workplace preferences. It evaluates the influence of gender on values of individuals in the workplace and the possible differences in how men and women experience the workplace values and preferences. It also investigates the relationship between gender and workplace values and examines whether women and men value the same things in a job and the extent to which female workers differ from male workers in terms of work values.

\section{Lite rature Review}

\subsection{Values}

Values are traits or qualities considered worthwhile; they represent highest priorities and deeply held driving

forces. As Bardi and Schwartz (2003) puts it values refer to the broad goals that apply across contexts and time although they can change in the long run. Values form the psychological core of the "self" and are standards from which beliefs, attitudes and, consequently, 
behaviours are shaped. Values include the constellation of likes, dislikes, viewpoints, inner inclinations, rational and irrational judgments, prejudices, and association patterns that determine a person's view of the world. The importance of a value system is that once internalized it becomes, consciously or subconsciously, a standard or criterion for guiding one's action.

Values are concepts or beliefs, about desirable end states or behaviours that transcend specific situations, guide selection or evaluation of behaviour and events, and are ordered by relative importance. A personal value system is viewed as a relatively permanent perceptual framework which shapes and influences the general nature of an individual's behaviour. Values are global beliefs about desirable end-states or modes of behaviour that underlie attitudinal processes and behaviour. They are beliefs upon which a person acts by preference. Values tend to be synonymous with emotional reactions, valuation ( $\mathrm{x}$ is more valuable than $\mathrm{y}$ ), goals, interests, needs, and outcomes. Thus, values are seen as inferable from behaviour, when the individual is aware of all available alternatives, can freely choose any particular one, and knows the probabilities of outcomes occurring.

Schwartz (2004) adds that values are desirable, trans-situational goals, varying in importance and serving as guiding principles in people's lives. The crucial aspect that distinguishes among values is the type of motivational goals they express. Schwartz derived 10 distinct motivational goals that are expressed as the following types of values: power, achievement, hedonism, stimulation, self direction, universalism, benevolence, tradition, conformity, and security.

Some values are incompatible, in the sense that actions undertaken in order to fulfil a certain value may conflict with the pursuit of other values. For example, behaviours engaged in the pursuit of stimulation values, which emphasize experiencing excitement, novelty, and challenge, are likely to impede the attainment of security values, which emphasize safety and stability. Competing values emanate in opposing directions while complementary values are in close proximity going around the circle.

Two explanations have been put forth as to why people behave according to their values. The first explanation

is that there is a need for consistency between one's beliefs (values) and action; the second is that value-consistent action is rewarding as it helps people attain satisfaction from this action. Rokeach (2008) observes that values are beliefs regarding preferable end-states of existence, which may serve to guide actions, attitudes, and judgements. Values justify attitudes and behaviour, as well as standards for morality. Values are also used as a means for comparison of selves with others and are specially used as criteria to judge and evaluate the actions of ourselves and others. Values are desirable trans-situational goals, varying in importance that serves as guiding principles in the life of a person or other social entity.

Schwartz (2004) affirms that values fulfil five criteria: (i) they are concepts or beliefs; (ii) they pertain to desirable end states or behaviours (iii) they transcend specific situations (iv) they guide selection or evaluation of behaviour and events and ( $v$ ) they are ordered by relative importance.

Agle and Caldwell (2009) suggests that values are an integral and daily part of our lives. They determine, regulate, and modify relations between individuals, organizations, 
institutions, and societies'. Values are central to the establishment of ongoing behaviour patterns. Values are not simply philosophical views rather they are related to behavioural goals and behavioural expectations. The value system influences behaviour and once a value is internalized, it becomes either consciously or unconsciously, a stand ard for guiding actions and making choices. The value then determines behaviours or modes of conduct. Values are at the basis of choice, the choices that people make reflect their perception of what is right, just, or what is cherished at a particular time. This underscores why it is best that values are understood and behaviours are in line with one's values. Men and women share workplace values with differing priorities.

\subsection{Gender and Workplace Values}

Moser (2010) affirms that gender is the difference between males and females within the same household and within and between socially and culturally construed changes over time. These differences are often in responsibilities, access to resources, contracts, opportunities, needs, perception and views. The issue of gender goes beyond possession of the subjective sense of male or female behaviours that are considered normal and appropriate for sex differentials.

Across all societies known to mankind, work has always occupied prime place in people's lives. However, the roles of female and males are usually defined in different cultures. Gender differences in the workplace typically stem from social factors, which influence the behaviors of males and females. Understanding what men and women value in a job is important to designing effective approaches to human resource management and in skill development initiatives.

According to studies, such as (Hepworth (2002); Gareth and Jennifer (2003); Sousa-Poza and Sousa-Poza (2000) and Guth and Taguiri (2007) male workers regard pay, benefits, authority, status and power noticeably more than do female workers. Women place their greatest workplace values on relationships, respect, communication, fairness, equity, collaboration and work-family balance. Interestingly, men do not tend to be especially aware of the factors that women value and women tend to overestimate how much men value money, status and power.

\subsection{Gender Workplace Traits}

Some social scientists theorize that work environments may embody either feminine or masculine attributes. Not surprisingly, experts may label nurturing, emotional, group-oriented and harmonious workplaces as feminine, while hierarchical, analytical, methodical and high-conflict workplaces may be labeled masculine. Different types of job environments may influence employment satisfaction. Gareth and Jennifer (2003) found that men and women in leadership positions tend to value nearly the same things i.e. interesting work in a supportive environment. According to the study, men felt their workplace needs were being met more frequently than women did, which might account for more women leaving their positions while men continued to advance.

Motivational factors have been studied and found to be remarkably 'different' for both the genders at a workplace. For instance Sousa-Poza and Sousa-Poza (2000) found that women 
show higher job satisfaction but lower commitment levels as compared to men, in the same work environment. Arising from the fact that different values appeal to the two genders, they tend to respond differently to opportunities, bonuses and rewards, etc. Women and men hold different perspectives on what is important and 'motivating' for good work performances. Results of studies like Hepworth et al (2002); Gareth and Jennifer (2003); Guth and Taguiri (2007) Hambrick and Mason (2004) suggest that distribution of basic and bonus rewards should be tied to specific preferences of both men and women based on how the two define satisfaction. Some factors attached to both genders affect their perceptions of rewards and satisfaction in the workplace. Hambrick (2009) observes that compared to women who go for 'softer issues' men place a higher preference on 'instrumental values'. Instrumental values cover basic salary and bonuses, while the softer-issues include inter-personal relationships at the workplace, respectful treatment by the employer and a possibility of reconciling work and family life. There is a marked gender-gap in the key driving forces of motivation and commitment. This can be further broken down into the following factors to see how differently men and women respond to motivational initiatives.

\subsection{Value Preference Variables}

This study seeks to find how differences in workplace values of females compare with those of males. The study tests for both females and males ten workplace value preference variables. The independent variables are (i) financial rewards (ii) competition (iii) emotions (iv) teamwork (v) training (vi) power (vii) Respect (viii) job flexibility (ix) acknowled gement (x) communication

\section{(i) Financial Rewards}

Financial rewards are the most traditional forms of motivating employees. Employees consider financial compensation as a very important factor in the workplace. However, while a pay raise would somewhat equally motivate both genders, studies like Medaiyese (2002), Kim (2005) and Majekodunmi (2008) reveal that men generally respond better to motivation through financial rewards. Therefore even though both genders are pleased to receive a bonus, men tend to work harder and seek a raise with greater anticipation than women. From a gender perspective, men place a higher value than women do on the 'instrumental values' (basic salary and bonuses) as a workplace value. Women, on the other hand, place more importance than men do on inter-personal relationships at the workplace, respectful treatment by the employer, and the possibility of reconciling work and family life. Women therefore seem to place more value on 'soft is sues'.

\section{(ii) Competition}

Basically, competition stimulates men in the workplace but, in the right work environment with a generally competitive group of employers, both men and women can be motivated through healthy and friendly competition. Kokemuller (2011) notes that the key to inducing healthy competition in the workplace is wise management. Where healthy competition is managed successfully; competition can motivate both genders into proving their gender and/or individual superiority.

\section{(iii) Emotions}

Women are generally noted to be more emotionally motivated at work. Consistent support and encouragement for a job done successfully drives women into higher levels of 
productivity. On the contrary, men seek motivation through the success (fruit of their effort) itself, and the power (such as a pay raise or elevation in their ranks) which they derive out of accomplishment and promotion.

\section{(iv) Teamwork}

Teamwork is an important topic in the current business climate as organizations are looking to team-based structures to stimulate further improvements to their productivity, profitability and service quality. Teamwork or group tasks are highly productive and popular gifts of the twenty-first century. The use of teams has spread rapidly arising from the belief that the development of strong and effective production and managerial teams will lead to the potential for higher performance and increased job satisfaction. There are synergies to be gained from greater levels of involvement in the workforce.

\section{(v) Training}

Training involves organized activities aimed at imparting information and/or instructions to improve the recipient's performance or to help him or her attain a required level of knowledge or skill. Training is of growing importance to companies seeking to gain an advantage among competitors. Employee training is a complex human resource practice that can significantly impact an organization's success.

\section{(vi) Power}

Power has to do with the ability to control, influence or direct. Power could be coercive or authoritative and the

employment relationship is essentially a power and authority relationship. Basic and Price (2003) identifies sources of power within the organization as: reward; coercive; legitimacy; reference or deference as well as expertise.

(vii) Respect

Respect constitutes a sensitive motivator in the workplace. For instance calling for workers input on improving business operations demonstrates respect for their opinions irrespective of their gender. This may increase their overall job satisfaction.

\section{(viii) Job Flexibility}

Gender theories and neo-classified theories both agree that job flexibility (in terms of hours and relatively easy entry, exist/re-entry) enable women to combine work and family responsibilities more easily. Men and women value job flexibility differently. The woman's responsibility for house work and child care affects the type of job many women prefer.

Two possible reasons have been adduced as to why women occupation tends to be flexible in terms hours and labour turnover. One is that women probably gravitate towards occupations where either because of women's preferences and characteristics and/or because employers prefer to employ women in these occupations. Second is that occupations become "female" because of the type of sex stereotyping just described with flexible working conditions emerging as a consequence of the fact that these are female occupations.

\section{(ix) Acknowledgement}

Acknowledgement motivates both the genders, but women respond more favourably to frequent acknowledgement. Saunderson (2008) states that women like to get verbal and written acknowledgement for work done more often than men do and therefore often respond more favourably to constant acknowledgment. However, where workplace recognition 
seems biased it hampers motivation both for male and female employees.

\section{(x) Communication}

Communication has to do with the ability to convey in the simplest form information or ideas which the

recipient can easily understand and an ability on the part of the recipient to reciprocate in a way that we can easily understand him. The emphasis is on the ability of the parties to share information, idea or attitude. Communication is a major and essential part of the work of any business organisation.

Communication is vital to every part of business. Male and female communication behaviours are affected by several social factors including ethnic culture, class, education, family norms, and most importantly the gender expectations and attitudes evoked in a particular context. A communication difference that arguably seems to have a biological basis is the tendency for females to be more accurate than males in reading non-verbal communication. The communication differences attributed to being male or female have more to do with differing relations of power 'and related socialization' than with innate communication abilities. Organizations that accommodate and encourage multiple communication styles in male and female employees have the greatest potential for successfully meeting complex communication needs.

\section{Research Hypotheses}

The following hypotheses were formulated for the study.

$\mathrm{H}_{0}$ : The value preference of financial rewards will not be significantly different for males and females.

$\mathrm{H}_{0}$ : The value preference of competition will not be significantly different for males and females.

$\mathrm{H}_{0}$ : The value preference of emotions will not be significantly different for males and females. $\mathrm{H}_{0}$ : The value preference of teamwork will not be significantly different for males and females. $\mathrm{H}_{0}$ : The value preference for training will not be significantly different for males and females. $\mathrm{H}_{0}$ : The value preference for power will not be significantly different for males and females. $\mathrm{H}_{0}$ : The value preference for respect will not be significantly different for males and females. $\mathrm{H}_{0}$ : The value preference for job flexibility will not be significantly different for males and females.

$\mathrm{H}_{0}$ : The value preference for acknowledgement will not be significantly different for males and females.

$\mathrm{H}_{0}$ : The value preference for communication will not be significantly different for males and females.

\section{Methodology}

The sample size used in this study was 250 workers made up of 125 each of males and females in both public and private sector organisations in Lagos Nigeria. However, of the 250 questionnaires administered only $238(90.2 \%)$ were returned in usable conditions. The 238 has $126(52.95 \%)$ males and $112(47.05 \%)$ females. Mean comparisons were used to determine whether there was a significant difference between the value preferences of male 
and female employees. Multivariate regression analysis was employed to examine the relationship between gender, and the value preference variables.

6. Results and Discussions

Table 1. Correlation between Gender and Workplace Value Variables

\begin{tabular}{|c|c|c|c|c|c|c|c|c|c|c|}
\hline \multirow[b]{2}{*}{$\begin{array}{l}\text { Gender } \\
\text { and }\end{array}$} & \multicolumn{6}{|c|}{ Independent Variables } & \multirow[b]{2}{*}{$\begin{array}{c}\text { Respe } \\
\text { ct }\end{array}$} & \multirow[b]{2}{*}{$\begin{array}{c}\text { Job } \\
\text { flexibilit } \\
y\end{array}$} & \multirow[b]{2}{*}{$\begin{array}{c}\text { Acknow } \\
\text { ledgeme } \\
\text { nt }\end{array}$} & \multirow[b]{2}{*}{$\begin{array}{l}\text { Communi } \\
\text { cation }\end{array}$} \\
\hline & $\begin{array}{l}\text { Financi } \\
\text { al } \\
\text { Reward } \\
\text { s }\end{array}$ & $\begin{array}{c}\text { Competiti } \\
\text { on }\end{array}$ & $\begin{array}{l}\text { Emotio } \\
\text { ns }\end{array}$ & $\begin{array}{l}\text { Teamwor } \\
\mathrm{k}\end{array}$ & $\begin{array}{c}\text { Trainin } \\
g\end{array}$ & $\begin{array}{c}\text { Powe } \\
\text { r }\end{array}$ & & & & \\
\hline \multicolumn{7}{|c|}{ Female } & & & & \\
\hline $\begin{array}{l}\text { Correlation } \\
\text { Coefficient }\end{array}$ & 0.68 & 0.65 & 0.64 & 0.59 & 0.54 & 0.44 & 0.61 & 0.62 & 0.44 & 0.57 \\
\hline $\begin{array}{l}\text { Significanc } \\
\text { e (2-tailed) }\end{array}$ & $<0.001$ & $<0.001$ & $<0.001$ & $<0.001$ & $<0.001$ & $\begin{array}{c}<0.00 \\
1\end{array}$ & $<0.001$ & $<0.001$ & $<0.001$ & $<0.001$ \\
\hline $\mathrm{N}$ & 112 & 112 & 112 & 112 & 112 & 112 & 112 & 112 & 112 & 112 \\
\hline \multicolumn{7}{|c|}{ Male } & & & & \\
\hline $\begin{array}{l}\text { Correlation } \\
\text { Coefficient }\end{array}$ & 0.64 & 0.66 & 0.58 & 0.54 & 0.63 & 0.67 & 0.52 & 0.53 & 0.47 & 0.54 \\
\hline $\begin{array}{l}\text { Significanc } \\
\text { e (2-tailed) }\end{array}$ & $<0.001$ & $<0.001$ & $<0.001$ & $<0.001$ & $<0.001$ & $\begin{array}{c}<0.00 \\
1\end{array}$ & $<0.001$ & $<0.001$ & $<0.001$ & $<0.001$ \\
\hline $\mathrm{N}$ & 126 & 126 & 126 & 126 & 126 & 126 & 126 & 126 & 126 & 126 \\
\hline
\end{tabular}

Table 1 presents correlation coefficients for the independent variable constructs for female and male respondents. The findings of the study reveal significant positive correlations $(\alpha<0.001)$ between gender and all the summated variables for both males and females. The differences in gender as the dependent variable and the independent variable constructs were investigated and the study hypotheses were also tested. Results from the regression reveal strong correlation between gender and the workplace value preferences for both females $(\mathrm{F}(10,1134)=314.35, \mathrm{p}<.001)$ and males $(\mathrm{F}(10,1153)=326.86, \quad \mathrm{p}<.001)$. Regression coefficients for all independent antecedent variables in both males and females were significant at $p<0.001$. Ten key drivers of workplace value preferences were tested for both females and males.

For the first hypothesis, the value preference for financial rewards was found to be positively correlated with gender. The males tended to value financial rewards more than the females. This confirms the position of studies like Medaiyese (2002), Kim (2005) and Majekodunmi (2008) all of which affirm that men generally respond better to motivation through financial rewards. Men and women differ in their perceptions of what is important and motivating for 
good work performance. The distribution of both intrinsic and extrinsic rewards should, therefore, be tied to the specific needs or preferences of men and women. Therefore while both genders are not opposed to financial reward men have higher value preference for financial rewards than women.

For the second hypothesis the study confirms that the value preference of competition was significantly different for males and females. The males also tended to have greater value preference for and appreciate competition more than the females.

The study found for the third hypothesis that value preference for emotions was significantly different for males and females. The females have a greater value preference for emotions than the men. Women are generally noted to be more emotionally motivated at work and value consistent support and encouragement for a job done than men.

In the fourth hypothesis, the value preference of teamwork was significantly different for males and females with the females placing greater value preference on teamwork. This confirms the position of an earlier study conducted in 2004 by North Western Institute of Policy Research, USA, which observes that teamwork is a more natural fit for women than men. Men tend to prefer autonomy at work, while women are more inclined to work with others and to build positive relationships with co-workers. Women, conversely, are better suited for 'communal behaviour', as compared to men.

For the fifth hypothesis there was no positive or significant correlation between gender and value preference for training. Opportunities that educate employees, fortify their knowledge and prove instrumental towards their career advancement are welcomed by both men and women. However, women may need these training programmes structured differently from men in consideration of the too many care-taking responsibilities they have which may affect their ability to attend full time and long period courses. Women may therefore respond better to 'skill-development days' instead of sessions that last for days, weeks and months. Again, trainings conducted during workdays keep women from having to take out extra time away from their domestic responsibilities. Men would however, readily welcome training programmes of all sorts, including the ones offered out of town.

There was also a positive and significant correlation between gender and value preference for power in

hypothesis six. A sense of importance is one of the main pursuits and generally, a crucial motivating factor for men. Men tend to have a strong inclination to seek greatness and to have sense of value. In the workplace, this would imply doing work that significantly impacts success of the organization. Clark (1997) observes that while women also yearn for importance, to men, it is the primary motive in many areas of life. Men are more hierarchical, while women tend to share power more equally and don't wield power in the same way men do. Basic and Price (2003) suggests that women have to manage power differently because both male and female subordinates expect women bosses to be more egalitarian when it comes to leading. The woman is expected to play down her power in a way a man doesn't have to worry about and while this is unfair it is true. In the same vein, Cox (2007) distinguishes between a goal focus and a process focus respectively between men and women in the workplace. Males are seen as the killers and women as the gatherers. 
For hypothesis seven, gender was found to have a positive and significant correlation with value preference for respect. This aligns with Akanji (2008) who asserts that to women respectful environment is an essential pre-requisite for working in an organization. Expressing consistent respect would naturally have women respond more positively than men, because women tend to hold 'soft-issues' dearer.

The value preference for job flexibility was significantly different for males and females in the eight hypothesis. Other studies have found gender differences in certain workplace flexibility issues. For instance a survey conducted by Opinion Research Corporation in 2009 found that 59 percent of working women place extra vacation days as one of their top three employment benefits, while only 47 percent of men give extra days off such a high priority.

For hypothesis nine the value preference for acknowledgement was found to be significantly different for males and females. For the tenth hypothesis, the value preference for communication was found to be positively correlated with gender. Akinsiku (2009) sees the communication style differences for men and women as "report talk" by men and "rapport talk" by women. Men expect to give a "report" to enhance their own power. Women use the opportunity of sharing information to help others gain the same level of knowled ge as they have, equalize the playing field and build rapport with others. In using "report talk" men frequently interrupt and compete for airtime; women wait to speak until others are heard. Communication is a basic requirement for the effective and efficient performance of management and supervisory tasks in all organizations. Effective Communication requires thought and attention to completeness, conciseness clarity, consideration, concreteness, correctness and courtesy. More often than not, women tend to put more emphasis on building relationships in the workplace than men do consequently women will communicate in a more relationship-building style. Women approach information sharing, listening, decision making, and the handling of conflicts and disagreements differently from men do. Understanding some of these differences in cross-gender communication styles give more choices in how to act. For instance while men tend to enjoy giving information as a way of showing expertise, women like sharing information to build relationships.

Factors associated with both genders affect their perceptions of values and belief systems in the workplace. For instance, some of the above value preferences may be indicative of why, women are found to be professionally under-represented among higher ranks in the corporate sector, around the world. Such trend can likely be diminished by promoting workplace values that would engage women, keeping their peculiar motivational factors in consideration, encouraging them to endeavor for higher positions in their organization so that gender balance can be attained in that area as well.

\section{Recommendations}

Promotion of gender equality in the workplace can be improved by ensuring that workplace values are gender sensitive thereby career prospects for women; creating a better work-life balance for both women and men; increasing the proportion of female workers in occupations, industries and particularly managerial positions that are currently male dominated.

Arising from the gender differences in the workplace values as identified in this study, it is recommended that human resource managers especially must not only be ready to alter their 
behaviours as the situation dictates they must be willing to accept other approaches from other people; the priority in the workplace being getting the work done to a quality level and in a timely fashion. The need for flexibility cannot be overemphasized. A single approach may not work at all times. For instance the need may arise as a human resource manager to be 'softer' when it will be more effective at building a relationship and gaining credibility. On the other hand, being authoritarian may sometimes be called for. Women and men bring different, but equally valuable assets to the organization. It is therefore wise for managers in addition to raising their awareness about the differences, to create an environment in which both genders are included and valued. Diverse opinions and perspectives added to a shared pool of knowledge bring about more creative problem-solving and better decision-making. Discrimination frequently occurs not as the result of intentional or malevolent intent, but from ignorance. Knowledge destroys ignorance and minimizes stereotyping. To be effective and to gain competitive advantage, human resource managers and practitioners must observe the behaviours and responses of organization members with an awareness of gender differences. Both individuals and teams in the organization must be educated and coached for inclusion and excellence. The need to raise awareness about gender differences cannot be overemphasized in addition to the importance of knowing audience and flexing to its communication style.

\section{Conclusion}

This study concludes that certain factors associated with both genders affect their perceptions of workplace values. Knowledge of the factors is useful in enhancing job satisfaction and boosting motivation because only a happy workplace is a healthy workplace, one that can sustain employees' longer and provide greater potential for growth. Both men and women have their own, peculiar strengths. The onus lies with the organization especially through the human resource department to understand those strengths and create an environment affording greater motivation, job satisfaction, level of commitment and consequently cultivate happiness in the organization.

\section{References}

Agle and Caldwell (2009) "Values and Value-orientation in the Theory of actions." In toward a general theory of action, edited by Talcott Pearson and Edward A. Shils. New York: Harper .388-433.

Akinsiku, S. (2009) Essential of Organization Communication, $5^{\text {th }}$ Edition, Oxford, Butterworth Heinemann.

Akanji, B.O. (2008). Female's Work in a Developing World: Implications for the Trade Union Movement. Proceedings of the $12^{\text {th }}$ Annual Dr. M. E. Kolagbodi Memorial Lecture. Lagos: A Publication of the Kolagbodi Memorial Foundation in Conjunction with Friedrich Ebert Stiftung.

Bardi, S. and Schwartz, J. (2003) Influence of founder-CEOs' personal values on firm performance: Moderating Effects of firm Age and Size: George Mason University, Enterprise Hall. 
Basic \& Price (2003) Human Resources Management in Business Context. Publishers Thomson learning High Holborn London.

Clark (1997) Clark, A. E. (1997). satisfaction and gender: Why are female so happy at work? Labour Economics, 4(4): 341-372.

Cox, J.O. (2007) Organizational structure and Managerial Decision Behavior". Administrative Science Quarterly, 13(1): 106-120

Fields, D., \& Blum, T. C. (1997). Workers satisfaction in work groups with different gender composition. Journal of Organizational Behavior, 18, 181-196.

Gareth and Jennifer (2003) An exploratory study of the personal value systems of college students and managers": The Academy Of Management Journal, 14(4):227-238.

Guth and Taguiri (2007) “The Sociology of Values”. Annual Review of sociology (27-49)

Hambrick and Mason (2004) The values construct”, Personally And Social Psychology Review, 4:255:77

Hambrick (2009) "Values and Value-orientation in the Theory of actions." In toward a general theory of action, edited by talcott

Pearson and Edward A. Shils. New York: Harper .388-433.

Hepworth et al (2002)" An exploratory study of the personal value systems of college students and managers": The Academy Of Management Journal, 14(4):227-238.

Kim, S. (2005). "Gender Differences in the Satisfaction of Public Workers: A Study of Seoul Metropolitan Government, Korea". Journal of Research in Sex and Roles, May 1, 2005.

Kokemuller Neil (2011) Gender Differences in Work Motivation e How.com http://www. ehow.com/info_8472175_gender-differences-work-motivation.html\#ixzz1TnFBolZX

Majekodunmi (2008) "Differences In Motivation and Satisfaction Among Female and Male Managers," Human Relations 35:101-18.

Medaiyese, T. Y. (2002) Determinants of Satisfaction of Federal Government Workers. Public Personnel Management, 26(3), 313-334.

Moser, A. (2010).Doing Gender, Doing Difference: Inequality, Power, and Institutional Change." New York, NY; Routled ge.

Rokeach M. (2008). Understanding Human Values, The free press, New York.

Saunderson, E.(2008), “A cross-national study of management values": Journal of International Business Studies, 27(4):739-748

Schwartz, S.H (2004), Toward a psychological structure of human values: Journal Of Personality and Social Psychology,:53: 550:562

Sousa-Poza, A., \& Sousa-Poza, A. A. (2000). Gender differences in satisfaction in Great Britain, 1991-2000: Permanent or transitory? Applied Economics Letters, 10(11): 691-694.

Wikipedia (2011). Gender Differentials. The Free Encyclopedia. Retrieved from www.google.com on $19^{\text {th }}$ November, 2012. 